\section{Case 2 (Jersey)}

A known drug user rushed into the drug clinic demanding that he was immediately given a naloxone minijet to take away. Although agitated, he was resourceful enough to request that the minijet was assembled for him, and he then departed in haste. Some 20 minutes later he returned, accompanied by a shaken overdose victim who had some 15 minutes earlier been comatose and blue. "I was very nervous putting a big needle in him. I didn't know what would happen, what the result would be, but once I did it there was an immediate result that was a good one. He was dead. He came back to life." The overdose victim was then taken by ambulance to the local accident and emergency department where he was observed and made a full recovery.

were actually given, each use cost around £33-67. Even if lives were saved on only $10 \%$ of these occasions, then each would have been saved at a drug cost of £330-670.

The range of doses given raises the possibility that naloxone was being titrated to effect resuscitation without provoking withdrawal. If so, recovery needs monitoring to avoid subsequent relapse into overdose. Some casualty departments and ambulance services now recommend giving naloxone intramuscularly or subcutaneously rather than intravenously because it can be given more quickly and results in less violent recovery. ${ }^{5}$ The same advice may apply to administration by peers. In future, family members may be trained to give emergency naloxone, ${ }^{3}$ for whom nonintravenous administration would be more realistic.

Early reports are encouraging. No adverse effects have been reported, and 10\% of distributed naloxone has saved lives. A study of the wider distribution of take home naloxone is now required.

$\mathrm{KD}$ is author on behalf of Ines Loska, Astrid Leicht, Johannes Korporal, Eckhart Holthaus, and Michael de Ridder. BS is author on behalf of colleagues at the drugs services at St Helier.

Contributors: JS originally proposed the distribution of naloxone as a strategy for overdose prevention and brought together the authors. KD and BS were responsible for the collection of the data. All three authors contributed to the final manuscript. $\mathrm{KD}$ and $\mathrm{BS}$ will act as guarantors for their respective data in the paper.

Competing interests: None declared.

1 Strang J, Darke S, Hall W, Farrell M, Ali R. Heroin overdose: the case for take-home naloxone? BMJ 1996:312:1435.

2 Darke S, Hall W. The distribution of naloxone to heroin users. Addiction 1997;92:1195-9.

3 Strang J. Take-home naloxone: the next steps. Addiction 1999;94:207.

4 Strang J, Powis B, Best D, Vingoe L, Griffiths P, Taylor C, et al. Preventing opiate overdose fatalities with take-home naloxone: pre-launch study of possible impact and acceptability. Addiction 1999;94:199-204.

5 Wanger K, Brough L, Macmillan I, Goulding J, MacPhail I, Christenson JM. Intravenous versus subcutaneous naloxone for out-of-hospital management of presumed opioid overdose. Acad Emerg Med 1999;5:293-9. (Accepted 13 December 2000)

\title{
Surgeons' attitudes to intraoperative death: questionnaire survey
}

\author{
Ian C Smith, M W Jones
}

Department of

Trauma and

Orthopaedics,

Ysbyty Gwynedd,

Bangor, Gwynedd

LL57 2PW

Ian C Smith

orthopaedic specialist

registrar

M W Jones

consultant

orthopaedic surgeon

Correspondence to:

I C Smith

lasoksmith@aol.com

BMJ 2001;322:896-7
Intraoperative death is a situation any surgeon might encounter. A news item in the BMJ discusses the outcome of an inquiry by Sheriff Albert Sheenan into an incident that involved the death of a patient having elective surgery. The inquiry recommended that a surgeon should not operate for a period of 24 hours after such an event because "the surgeon is ... not in the frame of mind to continue to operate that day."

After the intraoperative death of a trauma patient at our own hospital, we were advised by a defence association that the surgeons involved should not operate for the next 24 hours. Although we considered this advice surprising, as the patient had sustained injuries likely to be fatal irrespective of any intervention, we duly followed it. A later literature search failed to find any references considering the psychological state of surgeons after an intraoperative death. We decided to find out if there is a consensus of opinion among orthopaedic surgeons about how to cope with intraoperative death.

\section{Participants, methods, and results}

The proposal to carry out a survey was approved by the regional research ethics committee. Forty four consultants employed in Welsh health trusts and listed in the British Orthopaedic Association Handbook 1999 were sent questionnaires to be completed anonymously. The questions were related to the surgeons' experiences of intraoperative death, and were based on concerns raised by the Sheenan inquiry and related issues.

Thirty one $(70 \%)$ questionnaires were completed. Sixteen (53\%) acknowledged experience of intraoperative death. Five deaths $(31 \%)$ were expected trauma deaths, five (31\%) were unexpected trauma deaths, and five $(31 \%)$ were deaths during elective surgery. In one $(6 \%)$ death the respondent could not recall the category.

Of the 16 surgeons who experienced the intraoperative death of a patient, $13(81 \%)$ performed further operations that day. All those who continued to operate felt their competence had not deteriorated. Only one $(6 \%)$ did not operate when ordinarily he would have been expected to operate; he did so through personal preference and not as a result of external influences.

Eight $(50 \%)$ of the surgeons who experienced the death of a patient during surgery felt that some time without operating would have been advisable; of those not experiencing such an event, four $(26 \%)$ felt that this would be advisable.

None of those experiencing the death of a patient during surgery received or considered counselling. All five experiencing the death of a patient during elective surgery thought counselling should be offered. Four $(80 \%)$ of those experiencing unexpected intraoperative 
death of a trauma patient thought counselling should be offered, and one (20\%) of those experiencing expected intraoperative death of a trauma patient felt it should be offered.

\section{Comments}

There was no general consensus among the orthopaedic surgeons we surveyed about how to cope with intraoperative death. The nature of the specialty is reflected in the division between deaths during elective surgery and those relating to trauma. We were not surprised to find that all but one of the surgeons continued to operate and that the prevailing attitude was one of "it's part of the job."

A recent study considering stress levels in various medical specialties showed that stress levels are actually lowest in surgeons. ${ }^{2}$ We found no references specifically addressing surgeons' attitudes to intraoperative death, but our findings are not surprising as it has been suggested that surgeons are able to cope with situations that might be thought of as stressful to others. ${ }^{2}$
Because of the size of the study, we cannot draw conclusions about the difference in attitudes towards counselling between surgeons experiencing the death of a patient during elective surgery or an unexpected traumatic intraoperative death, and those experiencing an expected traumatic intraoperative death. We also acknowledge that we do not know whether counselling services were available nor whether the surgeons were aware of such services if they were available.

Contributors: ICS designed the questionnaire, wrote the paper, and conducted analyses and the literature search. MWJ proposed the original idea and arranged for the study to take place. ICS is the guarantor.

Funding: None.

Competing interests: None declared.

1 Christie B. Inquiry says surgeon should stop operating if patient dies. BMJ 1999;318:349.

2 Firth-Cozens J, Lema VC, Firth RA. Speciality choice, stress and personality: their relationships over time. Hospital Medicine 1999;60:751-5.

(Accepted 18 December 2000)

\section{Drug points}

\section{Benign intracranial hypertension secondary to nasal fluticasone propionate}

D W Bond, C P J Charlton, Department of Child Health, R M Gregson, Department of Ophthalmology, Queen's Medical Centre, University Hospital, Nottingham NG7 2UH

A 13 year old boy with Crohn's disease in remission presented with a 10 day history of head and back pain. He also mentioned intermittent blurring of vision and had developed a new squint four days before admission. He had a history of hay fever and was being treated with fluticasone propionate aqueous nasal spray $50 \mu \mathrm{g}$ to each nostril once a day (Glaxo Wellcome). This had been taken infrequently until five days before admission when our colleagues from the ear, nose, and throat department reviewed him and advised regular treatment.

On examination his optic discs were swollen bilaterally and he had a right sixth nerve palsy. Investigations showed no evidence of intercurrent infection. Urea and electrolytes, liver function, and concentrations of calcium, phosphate, and magnesium were all within normal limits. Fluorescein angiography showed leakage of dye from the optic discs, confirming mild bilateral papilloedema (figure). An unenhanced computed tomogram gave normal results. Cerebrospinal fluid was clear and colourless with no cells, and the protein concentration was $0.1 \mathrm{~g} / 1$ and glucose concentration $4.3 \mathrm{mmol} / \mathrm{l}$ (blood glucose $5.2 \mathrm{mmol} / \mathrm{l})$. The opening pressure of the cerebrospinal fluid was not measured. Magnetic resonance imaging excluded cavernous sinus thrombosis.

The fluticasone propionate was stopped, and over the next few weeks his headaches and back pain disappeared. His sixth nerve palsy resolved, and his disc margins cleared. On review five months later his optic discs had returned to normal and he had remained asymptomatic.

We propose that nasal fluticasone propionate caused this child's benign intracranial hypertension because of the temporal relation between symptoms to its regular administration. After lumbar puncture and the cessation of the drug his symptoms resolved over a few weeks and the papilloedema resolved over several months.

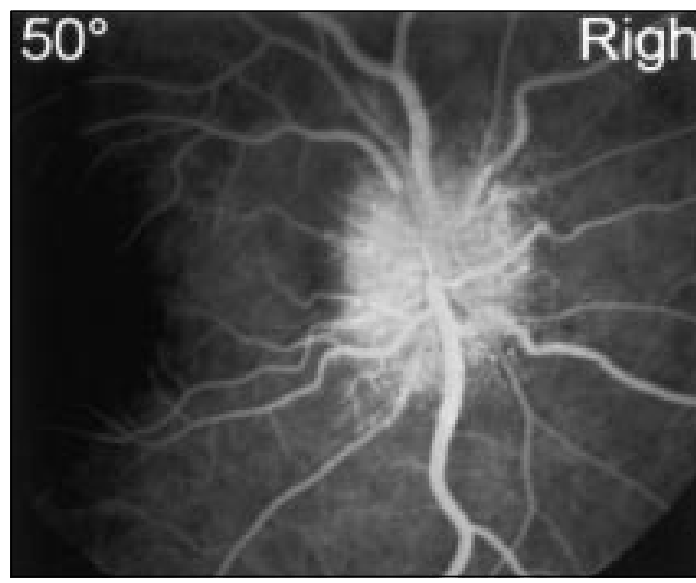

Disc swelling, vascular nipping, and vessel leakage shown by fluorescein angiography

The occurrence of benign intracranial hypertension is well documented with corticosteroids when given systemically ${ }^{1-3}$ or topically, ${ }^{14}$ together with their withdrawal. ${ }^{5}$ We reported this adverse reaction to the Committee on Safety of Medicines. The Medicines Control Agency and the manufacturers have confirmed that there have been no previous reports of benign intracranial hypertension with nasal fluticasone proprionate. Benign intracranial hypertension should be considered as a potential cause of headache in children taking nasal steroids.

\section{Competing interests: None declared.}

Grant DN. Benign intracranial hypertension: a review of 79 cases in infancy and childhood. Arch Dis Child 1971;46:651-5.

2 Vyas CK, Talwar KK, Bhatnagar V, Sharma BK. Steroid-induced benign intracranial hypertension. Postgrad Med J 1981;57:181-2.

3 Newton M, Cooper BT. Benign intracranial hypertension during prednisolone treatment for inflammatory bowel disease. Gut 1994;35:423-5.

4 Hosking GP, Elliston H. Benign intracranial hypertension in a child with excema treated with topical steroids. BMJ 1978;1:550-1.

5 Neville BGR, Wilson J. Benign intracranial hypertension following corticosteroid withdrawal in childhood. BMJ 1970;3:554-6. 